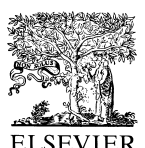

\section{Life Expectancy of Children in Vegetative and Minimally Conscious States}

\author{
David J. Strauss, PhD*, Stephen Ashwal, MD ${ }^{\dagger}$, Steven M. Day, MS*, and \\ Robert M. Shavelle, PhD*
}

We determined estimates of survival in children, 3-15 years of age, in the vegetative state (VS) $(n=564)$, immobile minimally conscious state $($ MCS $)(n=705)$, and mobile MCS $(n=3,806)$. Data were extracted from the annual Client Development Evaluation Reports of the California Department of Developmental Services between 1988 and 1997 using the operational definitions for these three states on the basis of $\mathbf{1 5}$ descriptive behavioral categories. Patients were also categorized according to the following four etiologies: acquired (traumatic and nontraumatic) brain injury; perinatal/genetic; degenerative; and unknown/undetermined. The percentage of patients surviving 8 years was $63 \%, 65 \%$, and $81 \%$, for the VS, immobile MCS, and mobile MCS, respectively. Children in the VS and MCSs with acquired brain injury had lower mortality rates and those with degenerative diseases the highest mortality rates. We observed little difference in survival between patients in the VS and immobile MCS, suggesting that the presence of consciousness is not a critical variable in determining life expectancy. Furthermore, survival was much greater for patients in the mobile MCS than for those in the immobile MCS, suggesting that mobility is more important in predicting survival than the level of consciousness. (C) 2000 by Elsevier Science Inc. All rights reserved.

Strauss DJ, Ashwal S, Day SM, Shavelle RM. Life expectancy of children in vegetative and minimally conscious states. Pediatr Neurol 2000;23:312-319.

\section{Introduction}

The Multi-Society Task Force on the Persistent Vegetative State defined the vegetative state (VS) as a condition of complete unawareness of the self and the environment, accompanied by sleep-wake cycles, with either complete or partial preservation of hypothalamic and brainstem autonomic functions [1]. The Aspen Consensus Conference workgroup on the vegetative and minimally conscious states described the minimally conscious state (MCS) as a condition of severely altered consciousness in which a person demonstrates minimal but definite behavioral evidence of self or environmental awareness [2]. Much has been written regarding survival of patients in the VS [3-17]. Relatively little, however, is known about survival of patients in the MCS. Knowledge of the survival and mortality rates for patients in these states can be valuable for the long-term planning of caregivers and family members.

In this study, we compared the mortality of children in the VS and MCS. Specifically, our goals were (1) to delineate the differences in survival and mortality risk for patients in the VS or MCS; (2) to identify the risk factors for a patient in the VS or MCS, such as the etiology of disability, presence of a gastrostomy tube for feeding, sex, age, or level of mobility (if any) in the MCS; and (3) to determine whether minimal consciousness, in the absence of mobility, is associated with better survival than the VS.

\section{Methods}

Test Instrument. We reviewed data collected by the California Department of Developmental Services on the Client Development Evaluation Reports (CDERs) [18] during the January 1988 to December 1997 study period. These data included observations on all 194,168 patients who received medical care or other services from the State of California during the study period. Each CDER during the study period included demographic information, ICD-9 codes for etiology, information on other medical conditions, and level of motor, self-care, and cognitive functioning. The CDER includes 261 items. Each patient's CDER is updated approximately annually, thus yielding repeated measures on risk factors for most patients in the study. The CDER has been previously validated, as reported in our earlier publications [4,17].
From the *Department of Statistics; University of California, Riverside, Riverside; and Department of Pediatrics; Loma Linda University School of Medicine, Loma Linda, California.
Communications should be addressed to:

Dr. Ashwal; Department of Pediatrics; Loma Linda University School of Medicine; 11175 Campus Street, Coleman Pavilion, Loma Linda, CA 92350.

Received April 12, 2000; accepted May 30, 2000. 
Table 1. Definitions of the VS, immobile MCS, and mobile MCS

\begin{tabular}{lccc}
\hline \hline & & \multicolumn{2}{c}{ Levels of Ability } \\
\cline { 2 - 4 } \multicolumn{1}{r}{ Description of CDER Item* } & VS & MCS & $\begin{array}{c}\text { Mobile } \\
\text { MCS }\end{array}$ \\
Rolling and sitting & & & \\
Hand use & 1 & 1 & $1-7$ \\
Arm use & 1 & 1 & $1-3$ \\
Eating & 1 & 1 & $1-4$ \\
Level of bladder control & 1 & 1 & 1 \\
Level of bowel control & 1 & 1 & 1 \\
One-to-one interaction with peers & 1 & 1 & 1 \\
Auditory perception & 1 & $1-2$ & $1-2$ \\
Visual perception & $1-2$ & $1-4$ & $1-4$ \\
Associating time with events & 1 & $1-5$ & $1-5$ \\
Word usage & 1 & 1 & 1 \\
Expressive nonverbal communication & 1 & $1-2$ & $1-2$ \\
Receptive nonverbal communication & 1 & $1-2$ & $1-2$ \\
Receptive language & 1 & $1-2$ & $1-2$ \\
Expressive language & 1 & $1-3$ & $1-3$ \\
& & &
\end{tabular}

* For details of the scales used, see the Appendix. Differences between immobile and mobile MCSs were based on different cutoff points in four categories: rolling and sitting, hand use, arm use, and expressive nonverbal communication. Hand use and arm use were included because higher levels of function require limb use.

Abbreviations:

CDER $=$ Client Development Evaluation Report

MCS = Minimally conscious state

VS $=$ Vegetative state

Subjects. Our subjects were patients who (1) received services from the California Department of Developmental Services between January 1988 and December 1997 and (2) were between 3 and 15 years of age and in the VS or MCS on at least one CDER during the study period. Only children 3 years of age and older were selected, because cognitive and communication deficits may not be apparent before that age. In all, 5,075 individuals met these criteria.

Mortality information was obtained by matching the annual computer tapes issued by the California Department of Health Services to the CDER database. According to California law, all deaths in the state are reported to that department.

Vegetative State. The definition of the VS used here is that proposed by Ashwal et al. [4] in a study using the same database. To be considered in a VS for a given CDER evaluation, a patient's scores must be at the lowest level on the 15 items of the CDER (Table 1). These items include evaluations of mobility, self-care, cognition, and communication. In other studies the reliability of these items has been investigated and judged satisfactory [19-22]. Previous studies have demonstrated that the survival and life expectancy of persons in the VS are considerably worse than those of the general population. Strauss et al. [17], using the same database as the present study, recently reported on the effect of a number of risk factors on the survival of patients in the VS.

Minimally Conscious States (With or Without Mobility). We used the operational definition of the MCS presented in Table 1. To be in a MCS on a given evaluation, a patient's scores must be better than the lowest level on at least one of the 15 items (better than the next-to-lowest in the case of Auditory Perception) but not so high as to demonstrate more than minimal behavioral evidence of one's self or the environment.

For patients with severe developmental disabilities, mobility proves to be a significant predictor of reduced mortality risk [23-30]. Mobility was defined as the presence of spontaneous or elicited movement of the trunk or upper or lower extremities, specifically the ability to lift one's head or chest when lying on the stomach, roll from front to back or back to front, or maintain the sitting position for at least 5 minutes. Our operational definition of the MCS allows for some mobility. With this in mind, we divided the MCS into two states: one with mobility and one without. A patient meeting the requirement for the MCS without evidence of mobility was considered to be in an immobile MCS. Otherwise the patient was in a mobile MCS.

Statistical Methods. We used the pooled repeated observation method for analysis. In this method the unit of observation is not a patient, but a patient-month. With each patient-month we associated (1) a binary outcome variable indicating whether the patient lived or died in that month and (2) a vector of explanatory variables, including age, sex, etiology, and so forth.

Logistic regression analysis [31] was used to relate the survival variable to the explanatory variables. This approach has been widely used in similar work [24-26]. The total patient-months contributed by 5,075 individuals during the study period was 200,057.5. During this period, 818 patients died, for an overall mortality rate of 49.1 deaths per 1,000 person-years.

We considered the following explanatory variables: (1) feeding tube (a binary variable indicating whether a patient was fed by gastrostomy tube); (2) sex (a binary variable for male/female); (3) state of consciousness (a binary variable for each of the three states: VS, immobile MCS, and mobile MCS); and (4) etiology (a binary variable for each of the four categories of etiology: acquired, perinatal/genetic, degenerative, and unknown/undetermined).

1. Acquired: a binary variable indicating whether the patient's disability was the result of a traumatic or nontraumatic brain injury. Patients with traumatic brain injury were identified either by an ICD-9 diagnosis of brain injury (codes $800-804$ or $850-854$ ) or by a cognitive disability arising from an automobile or other vehicular accident. Nontraumatic brain injuries were those acquired as the result of a near-drowning incident or suffocation; an infection such as measles or bacterial meningitis; or a cardiorespiratory arrest or cerebrovascular injury (e.g., stroke, hemorrhage).

2. Perinatal/genetic: A binary variable indicating whether a patient's disability originated in the perinatal period or from a nonprogressive genetic disorder such as Down syndrome (etiologies indicated in Table 2).

3. Degenerative: A binary variable indicating whether the patient's disability was caused by any of a number of degenerative diseases (Table 2).

4. Unknown/undetermined: A patient whose etiology did not fall into one of the above categories was referred to as "etiology not otherwise specified" (NOS). Approximately $40 \%$ of the children in the database had no etiology indicated in their reports.

Etiologic groupings were motivated by stratified analysis of mortality and by considerations of the medical similarities of the etiologies. Although the stratified analysis exhibited some evidence of a reduction in the mortality rates in the later part of the study period, the trend was inconsistent and weak. We did not include a secular trend, therefore, in our final model. Model selection was carried out using Wald and deviance statistics for nested models, and the Akaike information criterion otherwise [32]. We addressed the Markov assumption by including terms in the model representing a patient's present state, prior state, and all interactions. We found the prior state to be insignificant in predicting mortality.

\section{Results}

Table 2 presents the distribution of the 5,075 individuals in the study across the four etiologic groups. In $15.2 \%$ of patients the etiology was that of acquired brain injury; $43.2 \%$ had conditions that originated in the perinatal period, including chromosomal anomalies (mostly Down syndrome); and $2.1 \%$ had degenerative conditions. Approximately $40 \%$ of the patients were in the NOS group. 
Table 2. Etiology of vegetative state or minimally conscious state

\begin{tabular}{|c|c|c|}
\hline Etiology & $\mathbf{n}$ & $\%$ \\
\hline Traumatic brain injury* & 221 & 4.4 \\
\hline \multicolumn{3}{|l|}{ Other acquired brain injury } \\
\hline Near drowning or other post-natal asphyxia ${ }^{\dagger}$ & 213 & 4.2 \\
\hline $\begin{array}{l}\text { Infectious diseases, including of central nervous } \\
\text { system }\end{array}$ & 264 & 5.2 \\
\hline Cerebrovascular or pulmonary incidents ${ }^{\S}$ & 72 & 1.4 \\
\hline \multicolumn{3}{|l|}{ Perinatal/genetic } \\
\hline Congenital anomalies $\|$ & 612 & 12.1 \\
\hline $\begin{array}{l}\text { Other conditions originating in the perinatal } \\
\text { period }^{\text {II }}\end{array}$ & 774 & 15.3 \\
\hline Down syndrome ${ }^{\#}$ & 313 & 6.2 \\
\hline Other chromosomal anomalies** & 154 & 3.0 \\
\hline Other diseases of central nervous system ${ }^{\dagger \dagger}$ & 251 & 5.0 \\
\hline Metabolic disorders & 49 & 1.0 \\
\hline Maternal causes ${ }^{\S \S}$ & 31 & 0.6 \\
\hline Degenerative diseases $^{\|\|}$ & 106 & 2.1 \\
\hline Not otherwise specified ${ }^{\mathrm{TIII}}$ & 2015 & 39.7 \\
\hline TOTAL & 5,075 & 100.0 \\
\hline \multicolumn{3}{|c|}{$\begin{array}{l}* \text { ICD-9 codes } 800-804,850-854,310.2 \text {, and vehicle accidents as } \\
\text { indicated in CDER. }\end{array}$} \\
\hline \multicolumn{3}{|c|}{$\begin{array}{l}{ }^{\dagger} \text { ICD-9 codes } 933.0,933.1,934.1,934.8,934.9,994.1,994.7, \text { and } \\
\text { near drowning incidents as indicated in CDER. }\end{array}$} \\
\hline \multicolumn{3}{|c|}{ ₹ ICD-9 codes 003-139 and 320-326. } \\
\hline \multicolumn{3}{|l|}{ ICD-9 codes $410-438$} \\
\hline \multicolumn{3}{|l|}{ "ICD-9 codes $740-757$} \\
\hline \multicolumn{3}{|l|}{ II ICD-9 codes 764-779. } \\
\hline \multicolumn{3}{|l|}{ \# ICD-9 code 758.0} \\
\hline \multicolumn{3}{|c|}{$* *$ Other ICD-9 codes 758} \\
\hline \multicolumn{3}{|c|}{$\begin{array}{l}\text { ICD- } 9 \text { codes } 340-349 \text {, other than } 348.0 \text { or } 349.89 \text { (both } \\
\text { degenerative). }\end{array}$} \\
\hline \multicolumn{3}{|l|}{ ICD-9 codes $270-279$} \\
\hline \multicolumn{3}{|l|}{$\S \S$ ICD-9 codes $760-763}$. \\
\hline \multicolumn{3}{|c|}{$\begin{array}{l}\|\| \text { ICD-9 codes } 272.7,277.5,330.0-330.9,331.7,331.8,331.9,333.0 \\
\quad 333.1,333.2,333,334,348.0,349.89,437.0\end{array}$} \\
\hline \multicolumn{3}{|c|}{$\begin{array}{l}\text { III ICD-9 codes other than those indicated above, including } 799.9 \text {, } \\
999.9 \text { (approximately 49\%), or none indicated (approximately 40\%) } \\
\text { in CDER. }\end{array}$} \\
\hline \multicolumn{3}{|l|}{ Abbreviations: } \\
\hline \multicolumn{3}{|l|}{ CDER = Client Development Evaluation Report } \\
\hline ICD $=$ International Classification of Diseases, $N$ & th Revi: & \\
\hline
\end{tabular}

Details of the ICD-9 code groups are also displayed. Table 3 presents how the etiologies were distributed across the three conditions.

Table 4 presents the range of mobility observed in the

Table 3. Distribution of etiologies across the three states

\begin{tabular}{lccc}
\hline \hline & $\begin{array}{c}\text { VS } \\
(\mathbf{n}=\mathbf{5 6 4})\end{array}$ & $\begin{array}{c}\text { Immobile MCS } \\
(\mathbf{n}=\mathbf{7 0 5})\end{array}$ & $\begin{array}{c}\text { Mobile MCS } \\
(\mathbf{n}=\mathbf{3 , 8 0 6})\end{array}$ \\
& & & \\
Acquired (\%) & 36.5 & 22.1 & 10.7 \\
Perinatal/genetic (\%) & 32.1 & 39.3 & 45.4 \\
Degenerative (\%) & 2.8 & 4.3 & 1.6 \\
NOS (\%) & 28.6 & 34.3 & 42.4 \\
TOTAL (\%) & 100 & 100 & 100 \\
Abbreviations: & & & \\
MCS = Minimally conscious state & & \\
NOS = Not otherwise specified & & \\
VS = Vegetative state & & \\
\end{tabular}

Table 4. Level of mobility in mobile minimally conscious state group

\begin{tabular}{lrr}
\hline \hline \multicolumn{1}{c}{ CDER Criteria } & n & \% \\
& & \\
Rolling and sitting & 553 & 14.5 \\
1. Does not lift head when lying on stomach & 1,237 & 32.5 \\
2. Lifts head when lying on stomach & 335 & 8.8 \\
3. Lifts head and chest when lying on stomach & 435 & 11.4 \\
4. Rolls from side to side & 273 & 7.2 \\
5. Rolls from front to back only & 603 & 15.8 \\
6. Rolls from front to back and back to front & 370 & 9.7 \\
7. Maintains sitting position with minimal support & & \\
$\quad$ for at least 5 minutes & 3,806 & $100 \%$ \\
TOTAL & & \\
Hand use & 1,372 & 36.1 \\
1. No functional use of hand & 2,157 & 56.7 \\
2. Uses raking motion or grasps with hand & 277 & 7.3 \\
3. Uses thumb and fingers in opposition & & \\
4. Uses fingers independently & 3,806 & $100 \%$ \\
TOTAL & &
\end{tabular}

Data revealed that most patients who are in a mobile minimally conscious state still have very limited mobility as determined by their rolling and sitting ability and their hand use.

Abbreviation:

CDER $=$ Client Development Evaluation Report

mobile MCS group and demonstrates that the range of mobility in this group was actually quite limited. For example, only $9.7 \%$ of these patients were able to maintain a sitting position for 5 minutes, and more than $50 \%$ were unable to roll.

For children 3 years of age, the 8-year survival percentage was $63 \%, 65 \%$, and $81 \%$ for the VS, immobile MCS, and mobile MCS groups, respectively. Figure 1 illustrates the Kaplan-Meyer survival curves for the patients initially at 3 years of age in one of the three states. For children initially in the MCS, those with some mobility had markedly better survival than those without. The curves demonstrate that the difference in mortality for patients in the VS and immobile MCS was small.

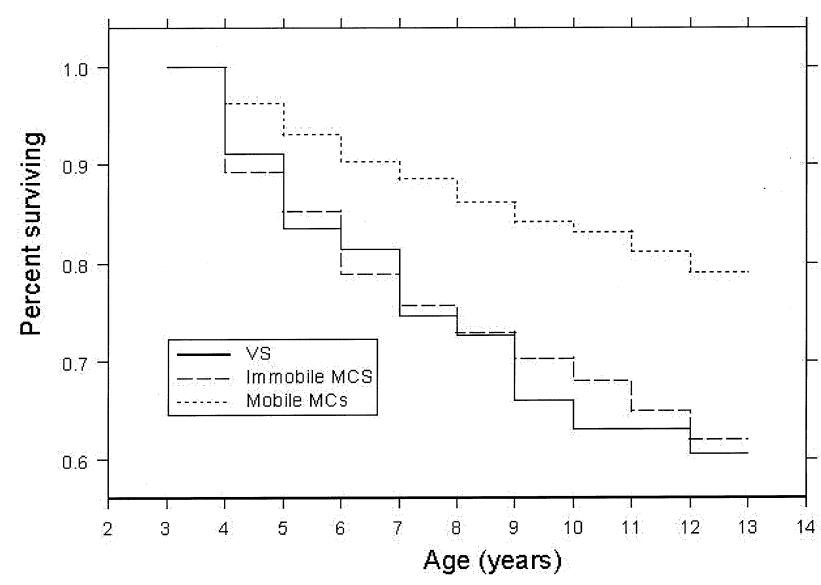

Figure 1. Kaplan-Meyer survival curves for a cohort of patients 3 years of age. Survival was similar in patients in a vegetative state (VS) and immobile minimally conscious state (MCS); those patients in a mobile MCS had a longer survival. 
Table 5. Logistic regression analysis of the affect of risk factors on mortality rates*

\begin{tabular}{|c|c|c|}
\hline Variable & $\begin{array}{l}\text { Odds } \\
\text { Ratio }^{\dagger}\end{array}$ & $\begin{array}{l}\text { 95\% Confidence } \\
\text { Interval }\end{array}$ \\
\hline \multicolumn{3}{|l|}{ Feeding status } \\
\hline Tube fed & 1.87 & $1.61-2.17$ \\
\hline Not tube fed & 1 & - \\
\hline \multicolumn{3}{|l|}{ State } \\
\hline VS & 1.87 & $1.53-2.27$ \\
\hline IMCS & 1.66 & $1.39-1.98$ \\
\hline MMCS & 1 & - \\
\hline \multicolumn{3}{|l|}{ Etiology } \\
\hline Acquired brain injury & 0.73 & $0.6-0.9$ \\
\hline Perinatal/genetic & 0.8 & $0.69-0.94$ \\
\hline Degenerative & 1.55 & $1.1-2.19$ \\
\hline NOS & 1 & - \\
\hline \multicolumn{3}{|c|}{$\begin{array}{l}* \text { Observation unit is one person-month rather than one person. } \\
{ }^{\dagger} \text { Mortality risk relative to the reference group, controlling for other } \\
\text { variables in the model. }\end{array}$} \\
\hline \multicolumn{3}{|c|}{ Abbreviations: } \\
\hline \multicolumn{3}{|c|}{ IMCS $=$ Immobile minimally conscious state } \\
\hline \multicolumn{3}{|c|}{ MMCS $=$ Mobile minimally conscious state } \\
\hline \multicolumn{3}{|c|}{ NOS $=$ Not otherwise stated } \\
\hline VS $\quad=$ Vegetative $\mathrm{st}$ & & \\
\hline
\end{tabular}

Table 5 gives the results of the logistic regression analysis. This multivariate analysis demonstrates the effects on mortality risk when other factors in the model were held fixed. Sex proved to be an insignificant risk factor and was omitted. The need for gastrostomy feeding was associated with a marked increase in mortality (odds ratio $1.87, P<0.0001)$. Consistent with the pattern in Figure 1 was the finding that mortality in the immobile MCS group was not significantly lower than in the VS group and that mortality in the mobile MCS group was significantly lower than in either $(P<0.01)$.

Both the acquired brain injury group and the perinatal/ genetic group had lower mortality rates than the NOS group (odds ratios 0.73 and 0.80 , respectively, $P<0.01$ ). As expected, patients with a degenerative etiology had a significantly higher risk of death than the comparison group (NOS) (odds ratio 1.55, $P<0.05$ ).

\section{Discussion}

Interest in defining and developing criteria for patients in the MCS has increased during the past decade [33-37]. This interest evolved because of concerns that some patients diagnosed as vegetative actually had evidence of limited awareness of themselves or the environment [38, 39]. Also at issue was whether the prognosis of patients in the MCS differed from those in the VS, particularly in relation to life expectancy and the potential for additional neurologic recovery. Data from the current study demonstrated little difference in survival between patients in the VS and those in an immobile MCS; those in the mobile MCS had a higher survival rate than those in the VS or immobile MCS.
It has been suggested that consciousness in itself, even though minimal, would increase survival, although the mechanisms of why and how this would happen remain unclear. It is apparent from the current data that consciousness alone is not the critical factor determining survival. By definition, patients in the VS are immobile, so examining "mobility" as a variable in this group is not relevant. Mobility can be examined in the MCS, and our data revealed a positive association between the presence of mobility and the duration of survival. Although consciousness alone does not increase survival, the presence of consciousness is associated with increased mobility, and it is the group of patients with increased mobility that have improved survival rates.

Although mobility is associated with improved survival in various populations of neurologically affected patients [23-30], the reasons for this improved survival have not been systematically studied. Mobility implies an intact or partially intact corticospinal tract and lower motor neuron function as a result of sufficiently preserved neurons and their descending pathways. Such patients are also likely to have preserved corticobulbar pathways with better brainstem function, resulting in improved sucking, swallowing, and respiratory control and postural, vestibular, and labyrinthine reflexes [40]. Mobile patients are better able to handle and mobilize nasopharyngeal and upper and lower airway secretions because of the improved mechanical function in these regions. This improvement reduces the risk of aspiration, gastroesophageal reflux, pooling of secretions, and atelectasis and the development of recurrent sinus and pulmonary infections [41-43]. Mobile patients are also less likely to have severe contractures, chest wall deformities, or scoliosis, which, when present, contribute to reduced ventilatory function [44-46]. Mobile patients are more likely to be fed orally than by gastrostomy tube and, as the present study and other studies [26] have demonstrated, oral feeding is associated with improved survival.

An important and repeatedly raised issue is that medical decision-making regarding withdrawing or withholding treatment from patients in the VS is influenced by the severe nature of their neurologic impairment $[35,47]$. Because vegetative patients are unconscious, they have been deemed to have lost personhood and be less worthy than patients who are severely impaired but who retain consciousness [35,47-51]. Information on the withdrawal of support is difficult to obtain for obvious reasons. However, the current data, demonstrating no difference in survival between patients in the VS and immobile MCS, may be indirect evidence that treatment decisions for patients in the VS are not being influenced by the assignment of less "value" or respect. We hope that explicit data on treatment decisions will become available, so that this issue can be studied directly.

Although the mobile MCS group might be perceived as having significant mobility and activity, it should be realized that their actual level of ability to move is quite 
limited. As presented in Table 1 and the Appendix, for rolling and sitting, the maximum activity that the patient in the mobile MCS can do is to maintain a sitting position with minimal support for at least 5 minutes. By our operational definition, patients in the mobile MCS were not able to sit without support for at least 5 minutes or to assume or maintain a sitting position independently. Thus the amount of "mobility" in this group was minimal (Table 4).

We were able to identify some effect of etiology on mortality risk. Within each of the three groups of patients, VS, immobile MCS, and mobile MCS, those with acquired brain injuries had lower mortality rates. Perhaps the lower mortality rate is a result of the acquired brain injury group having sounder health before injury compared with children with perinatal or genetic etiologies and a greater potential for recovery (particularly in the traumatic brain injury group). By contrast, children with degenerative diseases have a shorter survival than the other groups.

In our previous studies of patients in a persistent [4] or permanent [17] VS, we had created an "operational" definition of the VS on the basis of our clinical experience and the available CDER criteria. As stated earlier, we were able to validate these criteria. We developed a similar approach to operationally define MCS using the same CDER criteria but with different cutoff points (Table 1 and the Appendix). On the basis of the available published clinical information concerning the MCS [33,51-53], we believe that our operational definition is a reasonable and acceptable proxy for a clinically based determination of the MCS. The advantage to our approach is the ability to include a large number of patients with MCS monitored for an extended period, which allowed the study of important questions related to survival and the potential for recovery.

It has been estimated that 10,000-25,000 adults and 4,000-10,000 children are in the VS in the United States [1]. No estimates of the number of patients in the MCS have been reported. Of the 5,075 patients reported in this study, $11 \%(\mathrm{n}=564)$ were in the VS and $89 \%(\mathrm{n}=4,511)$ were in the MCS. If the proportion of patients in the VS to MCS were similar in the general U.S. population, it would suggest that between 112,000 and 280,000 adult and pediatric patients are in the MCS compared with the current estimates of 14,000-35,000 adult and pediatric patients in the VS.

Because of the limited study period (10 years), the median survival time in the three groups could not be determined; this calculation requires that $50 \%$ of the patients died. Thus, we could not directly compare the results of this study to our earlier studies of severely disabled children [26] or to children in a persistent [4] or permanent [17] VS. However, a comparison of the Kaplan-Meyer survival curves in these previous studies reveals that the patients in the current study have had a longer survival. This finding was not caused by a secular trend (i.e., improved survival caused by factors such as
Table 6. State of 1,715 children at 3 years old and 3 years later

\begin{tabular}{lrrrrrr}
\hline \hline & \multicolumn{5}{c}{ Condition 3 Years Later } \\
\cline { 2 - 7 } $\begin{array}{c}\text { Condition } \\
\text { at Age 3 }\end{array}$ & $\begin{array}{c}\text { Died } \\
(\boldsymbol{\%})\end{array}$ & $\begin{array}{c}\text { VS } \\
(\boldsymbol{\%})\end{array}$ & $\begin{array}{c}\text { IMCS } \\
(\boldsymbol{\%})\end{array}$ & $\begin{array}{c}\text { MMCS } \\
\mathbf{( \% )}\end{array}$ & $\begin{array}{c}\text { Better } \\
(\boldsymbol{\%})\end{array}$ & $\begin{array}{c}\text { Total } \\
(\boldsymbol{\%})\end{array}$ \\
VS (n = 163) & 14 & 58 & 7 & 9 & 12 & 100 \\
IMCS (n =176) & 13 & 1 & 52 & 15 & 18 & 100 \\
MMCS & 7 & 0 & 1 & 54 & 38 & 100 \\
$\quad(\mathrm{n}=1,376)$ & & & & & &
\end{tabular}

Abbreviations as in Table 5.

better health care). Instead, the difference reflects the different questions addressed here and in the previous studies. Specifically, the earlier studies applied to children in a persistent or permanent VS. In the present study, by contrast, no assumption of persistence or permanence was made. For example, some patients start out in the VS and improve to the immobile or mobile MCS or some better state. We observed, for instance, that of the 3-year-old patients who started out in a given state, only slightly more than one half were in the same state 3 years subsequently (Table 6). We hope to investigate this question of a change of state further in a subsequent study and determine whether differences exist in the rate or magnitude of recovery in patients in the VS, immobile MCS, and mobile MCS.

We thank Drs. Ron Cranford, Joseph Giacino, Deborah Hirtz, Sarah Roddy, and Stanford Shu for their helpful comments and review of the manuscript.

\section{References}

[1] Multi-Society Task Force on the Persistent Vegetative State. Medical aspects of the persistent vegetative state, part I. N Engl J Med 1994;330:1499-508.

[2] Aspen Consensus Conference. Workgroup on the vegetative and minimally conscious states. Presented at the Biomedical Institute, March 19-23, 1996, Aspen, Colorado.

[3] Multi-Society Task Force on the Persistent Vegetative State. Medical aspects of the persistent vegetative state, part II. N Engl J Med 1994;330:1572-79.

[4] Ashwal S, Eyman RK, Call TL. Life expectancy of children in a persistent vegetative state. Pediatr Neurol 1994;10:27-33.

[5] Haig AJ. The persistent vegetative state (letter). N Engl J Med 1994;331:1380.

[6] Katz RT, Haig AJ, Clark BB. Long-term survival, prognosis, and life-care planning for 29 patients with chronic locked-in syndrome. Arch Phys Med Rehabil 1992;73:403-8.

[7] Higashi K, Sakata Y, Hatano M, et al. Epidemiological studies on patients in persistent vegetative state. J Neurol Neurosurg Psychiatry 1977;40:876-85

[8] Higashi K, Hatano M, Abiko S, et al. Five year follow-up study of patients with persistent vegetative state. J Neurol Neurosurg Psychiatry 1981;44:552-4.

[9] Sazbon L, Groswasser Z. Outcome in 134 patients with prolonged posttraumatic unawareness. I: Parameters determining late recovery of consciousness. J Neurosurg 1990;72:75-80.

[10] Sazbon L, Groswasser Z. Medical complications and mortality of patients in the postcomatose unawareness (PC-U) state. Acta Neurochir 1991;112:110-2. 
[11] Roberts A. Severe accidental head injury: An assessment of long-term prognosis. London: Macmillan Press, 1979.

[12] Lewin W, Marshall TFD, Roberts AH. Long-term outcome after severe head injury. BMJ 1979;2:1533-8.

[13] Tresch DD, Sims FS, Duthie EH, Goldstein MD, Lane PS Clinical characteristics of patients in the persistent vegetative state. Arch Intern Med 1991;151:930-32.

[14] Vollmer DG, Torner JC, Jane JA, et al. Age and outcome following traumatic coma: Why do older patients fare worse. J Neurosurg 1991;75:S37-49.

[15] Zafonte RD, Hammond FM, Peterson J. Predicting outcome in the slow to respond brain-injured patient: Acute and subacute parameters. Neurorehabilitation 1996;6:19-32.

[16] Minderhoud JM, Braakman R. Het vegeterende bestaan. Ned Tijdschr Geneeskd 1985; 29:2385-8.

[17] Strauss DJ, Shavelle RM, Ashwal S. Life expectancy and median survival time in the permanent vegetative state. Pediatr Neurol 1999;21:626-31.

[18] California Department of Developmental Services. Client Development Evaluation Report. Sacramento: 1978.

[19] Arias M, Ito E, Takagi N. Concurrent validity of the Client Development and Evaluation Report. In Silverstein AB, Fluharty AL, eds. Pacific State Archives VIII. Pomona, California: University of California, Los Angeles, Developmental Disabilities Immersion Program, 1983:28-33.

[20] Harris CW, Eyman RK, Mayeda T. An interrater reliability study of the Client Development Evaluation Report: Final report to the California Department of Developmental Disabilities. Los Angeles: UCLA Mental Retardation Research Center, Lanterman State Hospital, 1982.

[21] Widaman KF. Interrater reliability of adaptive behavior assessments: Item and factor levels. Presented at the 92nd Annual Meeting of the American Psychological Association, Toronto, Ontario, August 1984.

[22] Widaman KF, Stacy AW, Borthwick SA. Multitrait-multimethod of evaluating adaptive and maladaptive behavior of mentally retarded people. Presented at the 109th Annual Meeting of the American Association on Mental Deficiency, Philadelphia, 1985.

[23] Eyman RK, Strauss DJ, Grossman HJ. Survival of children with severe developmental disability. In Rosenbloom L, ed. Diagnosis and management of neurological disabilities in childhood. In Bailliere's clinical pediatrics. London: Baillière Tindall, Harcourt Brace, 1996:54356.

[24] Strauss DJ, Kastner TA. Comparative mortality of people with developmental disability in institutions and in the community. Am J Ment Retard 1996;101:26-40.

[25] Strauss DJ, Kastner TA, Shavelle RM. Mortality in persons with developmental disabilities, 1985-94. Ment Retard 1998;30:368-91.

[26] Strauss DJ, Kastner TA, Ashwal S, White JF. Tubefeeding and mortality in children with severe disabilities and mental retardation. Pediatrics 1997;99:358-62.

[27] Strauss DJ, Shavelle RM. Life expectancies of persons with chronic disabilities. J Insurance Med 1998;30:96-108.

[28] Strauss DJ, Shavelle RM. Life expectancy of adults with cerebral palsy. Dev Med Child Neurol 1998;40:369-75.

[29] Strauss DJ, Shavelle RM, Anderson TW. Life expectancy of children with cerebral palsy. Pediatric Neurol 1998;18:143-49.

[30] Strauss DJ, Shavelle RM, Anderson TW. Long-term survival of children and adolescents after traumatic brain injury. Arch Phys Med Rehab 1998;79:1095-1100.

[31] Hosmer DW, Lemeshow S. Applied logistic regression. New York: Wiley, 1989.

[32] Collett D. Modelling survival data in medical research. London: Chapman \& Hall, 1994.

[33] Giacino JT, Kalmer K. The vegetative and minimally conscious states: A comparison of clinical features and functional outcome. J Head Trauma Rehabil 1997;12:36-51.

[34] Phipps E, Whyte J. Medical decision-making with persons who are minimally conscious: A commentary. Am J Phys Med Rehabil 1999;78:77-82.

[35] Nelson LJ, Cranford RE. Michael Martin and Robert Wendland: Beyond the vegetative state. J Contemp Health Law Policy 1999;15:42753.

[36] Cranford RE. The vegetative and minimally conscious states: Ethical implications. Geriatrics 1998;53(Suppl 1):S70-3.

[37] Giacino JT. Disorders of consciousness: Differential diagnosis and neuropathologic features. Semin Neurol 1997;17:105-11.

[38] Childs NL, Mercer WN, Childs HW. Accuracy of diagnosis of persistent vegetative state. Neurology 1993;43:1465-7.

[39] Andrews K, Murphy L, Munday R, Littlewood C. Misdiagnosis of the vegetative state: Retrospective study in a rehabilitation unit. BMJ 1996;313:13-6.

[40] DeToledo J, Icovinno J, Haddad H. Swallowing difficulties and early CNS injuries: Correlation with the presence of axial skeletal deformities. Brain Inj 1994;8:607-11.

[41] Mackay LE, Morgan AS, Bernstein BA. Swallowing disorders in severe brain injury: Risk factors affecting return to oral intake. Arch Phys Med Rehabil 1999;80:365-71.

[42] Martin BJ, Corlew MM, Wood H, et al. The association of swallowing dysfunction and aspiration pneumonia. Dysphagia 1994;9: $1-6$.

[43] Kohda E, Hisazumi H, Hiramatsu K. Swallowing dysfunction and aspiration in neonates and infants. Acta Otolaryngol Suppl 1994; 517:11-6.

[44] Saito N, Ebara S, Ohotsuka K, Kumeta H, Takaoka K. Natural history of scoliosis in spastic cerebral palsy. Lancet 1998;351:1687-92.

[45] DeToledo JC, Haddad H. Progressive scoliosis in early, nonprogressive CNS injuries: Role of axial muscles. Brain Inj 1999;13:3943.

[46] Majd ME, Muldowny DS, Holt RT. Natural history of scoliosis in the institutionalized adult cerebral palsy population. Spine 1997;22: 1461-6.

[47] Broder AJ, Cranford RE. "Mary, Mary, Quite Contrary, How Was I To Know? Michael Martin, absolute prescience, and the right to die in Michigan. University of Detroit Mercy Law Review 1995;72:787832.

[48] Payne K, Taylor RM, Stocking C, Sachs GA. Physicians' attitudes about the care of patients in the persistent vegetative state: A national survey. Ann Intern Med 1996;125:104-10.

[49] McLean SA. Legal and ethical aspects of the vegetative state. J Clin Pathol 1999;52:490-3.

[50] Gillon R. Persistent vegetative state, withdrawal of artificial nutrition and hydration, and the patient's "best interests. " J Med Ethics 1998;24:75-6.

[51] Whyte J, DiPasquale MC, Vaccaro M. Assessment of command-following in minimally conscious brain injured patients. Arch Phys Med Rehabil 1999;80:653-60.

[52] Pilon M, Sullivan SJ. Motor profile of patients in minimally responsive and persistent vegetative states. Brain Inj 1996;10:421-37.

[53] Piguet O, King AC, Harrison DP. Assessment of minimally responsive patients: Clinical difficulties of single-case design. Brain Inj 1999;13:829-37.

\section{Appendix}

\section{Client Development Evaluation Report Items Used in Definitions of VS, Immobile MCS, and Mobile MCS}

\section{Rolling and Sitting}

1. Does not lift head when lying on stomach

2. Lifts head when lying on stomach 
3. Lifts head and chest using arm support when lying on stomach

4. Rolls from side to side

5. Rolls from front to back only

6. Rolls from front to back and back to front

7. Maintains sitting position with minimal support for at least 5 minutes

8. Sits without support for at least 5 minutes

9. Assumes and maintains sitting position independently

\section{Hand Use}

1. No functional use of hand

2. Uses raking motion or grasps with hand

3. Uses thumb and fingers in opposition

4. Uses fingers independently of each other

\section{Arm Use}

1. No functional use of arm

2. Moves arm from shoulder but does not extend or flex arm (i.e., does not have control of elbow joint)

3. Partially extends arm

4. Fully extends arm

\section{Eating}

1. Does not feed self, must be fed completely

2. Attempts to finger feed but needs assistance

3. Finger feeds self without assistance

4. Feeds self using spoon, with spillage

5. Feeds self using fork and spoon, with spillage

6. Uses eating utensils with no spillage

\section{Level of Bladder Control}

1. No control

2. Some bladder control, accidents during waking hours (once a week or more)

3. Control during day, wets at night

4. Complete control

\section{Level of Bowel Control}

1. No control

2. Some bowel control, accidents during waking hours (once a week or more)

3. Control during day, soils at night

4. Complete control

\section{One-to-One Interaction With Peers}

1. Does not enter into interaction

2. Enters into interaction only when others initiate

3. Initiates interaction in familiar or previously successful situations or settings

4. Initiates interaction in both familiar and unfamiliar situations or settings

Auditory Perception

1. Does not react to sounds

2. Demonstrates startle response to loud sounds

3. Turns head or eyes toward sound source
4. Responds differently to voices compared with other sounds (by smiling or paying attention to the voices)

5. Responds to voices of familiar people differently from strangers' voices

6. Recognizes words that sound different ("cat" and "door")

7. Recognizes words that sound the same ("hit" and "sit")

Visual Perception

1. Does not explore visually (includes continuous staring)

2. Some visual exploration but does not follow moving objects

3. Eyes follow moving objects

4. Rotates head and inspects surroundings (if no motor limitations)

5. Searches for object that disappears from sight

6. Responds differently to grossly different objects (a ball and a pencil)

7. Responds differently to similar objects (a cat and a dog)

8. Responds differently to objects (based on differences of color, size, or shape)

Associating Time With Events and Actions

1. Does not associate events and actions with time

2. Associates regular events with morning, noon, or night

3. Associates regular events with a specific hour (dinner at $6 \mathrm{PM})$

4. Associates events with specific time in past, present, or future (the ball game is at 6 PM tomorrow)

Word Usage

1. No use of words

2. Uses simple (one-syllable) words and associates words with appropriate objects

3. Uses complex words and associates words with appropriate objects but has a limited vocabulary

4. Has a broad vocabulary, understands meaning of words, and uses them in appropriate context

Expressive Nonverbal Communication

1. No expressive nonverbal communication

2. Expresses needs or reactions by squirming, returning smiles, etc.

3. Communicates by pointing, shaking head, leading by the hand, etc.

4. Gestures with hands, uses facial expressions for communication

\section{Receptive Nonverbal Communication}

1. Does not demonstrate understanding of gestures (tactile or visual) or facial expressions

2. Demonstrates understanding of simple gestures ("yes," "no," pointing to an object)

3. Demonstrates understanding of complex gestures

4. Demonstrates understanding of a series of gestures (tactile or visual) 
Receptive Language

1. Does not understand speech

2. Understands simple words

3. Understands simple phrases or instructions

4. Understands meaning of simple conversation and combination of verbal instructions

5. Understands meaning of story plot and complex conversation
Expressive Language

1. Makes no sound

2. Babbles but says no words

3. Says simple words

4. Says two-word sentences ("I go," "give me," etc.)

5. Says sentences of three or more words

6. Carries on a conversation

7. Carries on more complex conversation 